\title{
Ultrastructural aspects of infection with Treponema pallidum subspecies pertenue (Pariaman strain)
}

\author{
H J H Engelkens, V D Vuzevski, F J W ten Kate, P van der Heul, J J van der Sluis, E Stolz
}

\begin{abstract}
Objective-To study ultrastructural aspects of infection with Treponema pertenue (Pariaman strain), originating from West Sumatra, Indonesia.

Materials and methods-Biopsy material originating from skin lesions in ten young children suffering from early infectious yaws in Indonesia, and rabbit testicular tissue inoculated with $T$ pertenue. Human skin as well as rabbit testicular tissue was examined by means of conventional electron microscopy. Results-In human skin, treponemes were found in interepidermal spaces in 5 out of 10 specimens. In two of five positive specimens, treponemes were also seen in the dermis. In one out of five specimens from rabbit testicular tissue a profusion of treponemes was found lying in the interstitial myxomatous tissue. Microorganisms showed no adhesion to fibroblasts.

Conclusion-This ultrastructural study of $T$ pertenue demonstrated the scarcity and focal distribution of treponemes in tissue and did not reveal any morphological differences from the Gauthier strain of $T$ pertenue. No differences from the ultrastructure of $T$ pallidum were observed either.
\end{abstract}

\section{Introduction}

Yaws (framboesia tropica, buba, pian, patek) was not eradicated after mass treatment campaigns in the $1950 \mathrm{~s}$ and 1960s. This led to the persistence or resurgence of endemic foci in tropical regions, from where the disease is spreading rapidly. ${ }^{1-3}$ The causative agent of yaws is Treponema pallidum subspecies pertenue ( $T$ pertenue), which cannot be distinguished morphologically or serologically from

Department of Dermatology and Venereology, University Hospital Rotterdam-Dijkzigt and Erasmus University Rotterdam, The Netherlands H J H Engelkens, J J van der Sluis, E Stolz

Department of Clinical Pathology, Faculty of Medicine, Erasmus University, Rotterdam, The Netherlands

V D Vuzevski, F J W ten Kate, P van der Heul
Treponema pallidum subspecies pallidum ( $T$ pallidum), the causative agent of venereal syphilis. However, there are clinical, geographic and epidemiologic differences between the different treponematoses. ${ }^{14} T$ pertenue cannot be cultured in vitro for prolonged periods of time. For laboratory investigations, treponemes are preferably propagated in rabbits or hamsters.

Literature on the ultrastructure of $T$ pertenue is extremely scarce. ${ }^{5-8}$ Most recent work has been restricted to the study of the Gauthier strain, which was isolated from a patient in Nigeria in $1960 . .^{78}$ During investigations in 1988 cases of infectious yaws were detected in West Sumatra, Indonesia. ${ }^{910}$ In Rotterdam, a strain of $T$ pertenue (Pariaman strain) has recently been adapted to the rabbit. We investigated this strain in patient as well as in rabbit material by means of conventional electron microscopy and compared our findings with earlier publications on the morphology of $T$ pertenue.

\section{Material and methods}

Biopsy material was studied, originating from skin lesions of ten patients. All patients were young children, presenting with florid skin lesions of the early stage of yaws in West Sumatra, Indonesia. ${ }^{910}$ Six children presented with crusto-papillomatous skin lesions, two with ulcero-papillomatous and two with ulcero-crusto-papillomatous skin lesions. Treponemal and non-treponemal serologic tests and darkfield examination of exudates from skin lesions were positive in all patients. Immediately after obtaining the specimens, fixation of small fragments was performed in a solution of glutaraldehydeformaldehyde (4CF-1G). The specimens were transported from Sumatra to Rotterdam.

Further, treponemes were propagated in laboratory animals. In Indonesia, treponemecontaining suspensions obtained from patients were inoculated into Syrian Golden hamsters, which were transported to the Netherlands. After several weeks, when skin lesions had developed in the inguinal region, lymph nodes were removed. Treponemecontaining suspensions obtained from the lymph nodes (checked by darkfield examination) were injected intratesticularly in New Zealand white rabbits. 


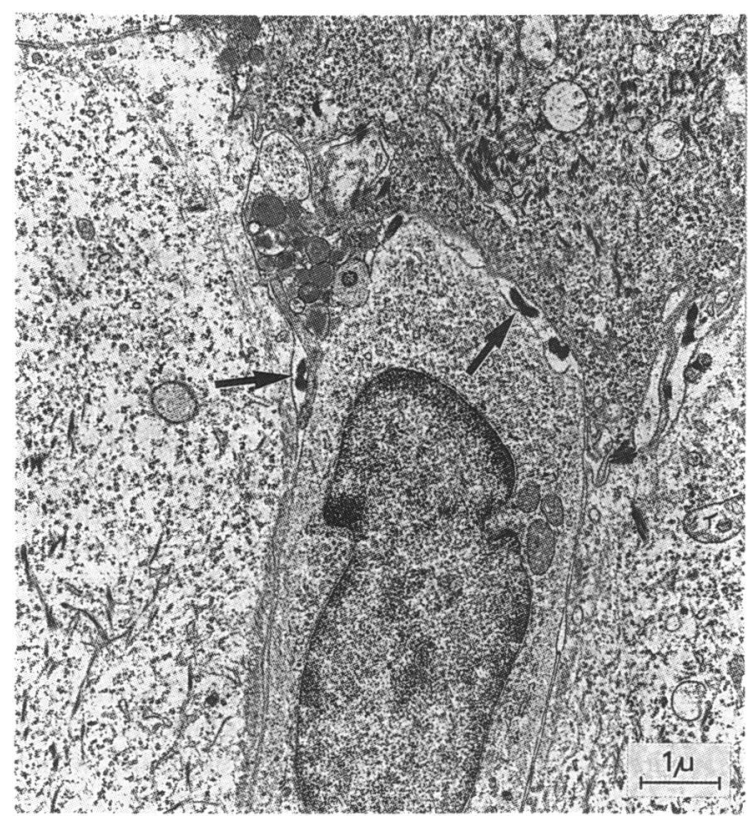

Figure 1 Human tissue. In the interepidermal space adjacent to inflammatory cells there are numerous treponemes (arrows) lying free or lying close to the membrane of inflammatory cells (magnification $7000 \times$ ).

These animals, about four kg weight and about 6 to 8 months old, were obtained from a commercial breeding farm. All rabbits developed a positive treponemal serology after two to four weeks. The testes were removed aseptically as soon as palpable changes were present. Compact nodules of only a few $\mathrm{mm}$ in diameter appeared on the testis in most cases. Multiple small fragments from these small nodules and the other testicular tissue were fixed immediately in glutaraldehyde-formaldehyde. After fixation, all tissue was postfixed with $1 \%(\mathrm{w} / \mathrm{v})$ osmium tetroxide at $4^{\circ} \mathrm{C}$. After acetone dehydration, the specimens were embedded in LX 112 (Epon). Semi-thin plastic sections for light microscopy were stained with a freshly prepared $1 \%$ toluidine blue solution in distilled water. Ultrathin sections (LKB ultratome IV) were mounted on copper grids (300 mesh) and contrasted with uranyl acetate $\left(10\right.$ minutes at $\left.45^{\circ} \mathrm{C}\right)$ and lead citrate. They were examined with a Zeiss 902 electron microscope. In all specimens $T$ pertenue were detected by silver impregnation.

\section{Results}

Ultrastructural features

Electron microscopy showed an undulating appearance of $T$ pertenue, changing in amplitude and frequency (fig 1). Treponemes had a width of approximately 0.11 to $0.17 \mu \mathrm{m}$. They were surrounded by a cytoplasmic membrane and an outer membrane, both consisting of three layers. In only a few treponemes a clear space was observed between the outer membrane and the cytoplasmic membrane. Flagella (axial filaments) were clearly visible, lying between the outer membrane and peptidoglycan layer (fig 2).

Treponemes were detected in five out of ten specimens of human tissue, in the intercellular spaces of the epidermal layer and among the inflammatory cells (fig 3). In some lesions the microorganisms were also found in the cytoplasm of the macrophages. These treponemes were observed in a membranous sac within the cytoplasm, a phagosome-like structure. The cellular membrane was clearly preserved. In the epidermis treponemes were lying in intercellular spaces, between the keratinocytes. At some locations $T$ pertenue appeared to be in close contact with the epidermal cells, which ultrastructurally showed no signs of damage (fig 3 ). In two cases only a few treponemes were observed in the dermis (fig 4). In most positive samples treponemes were scarce, located in clusters.

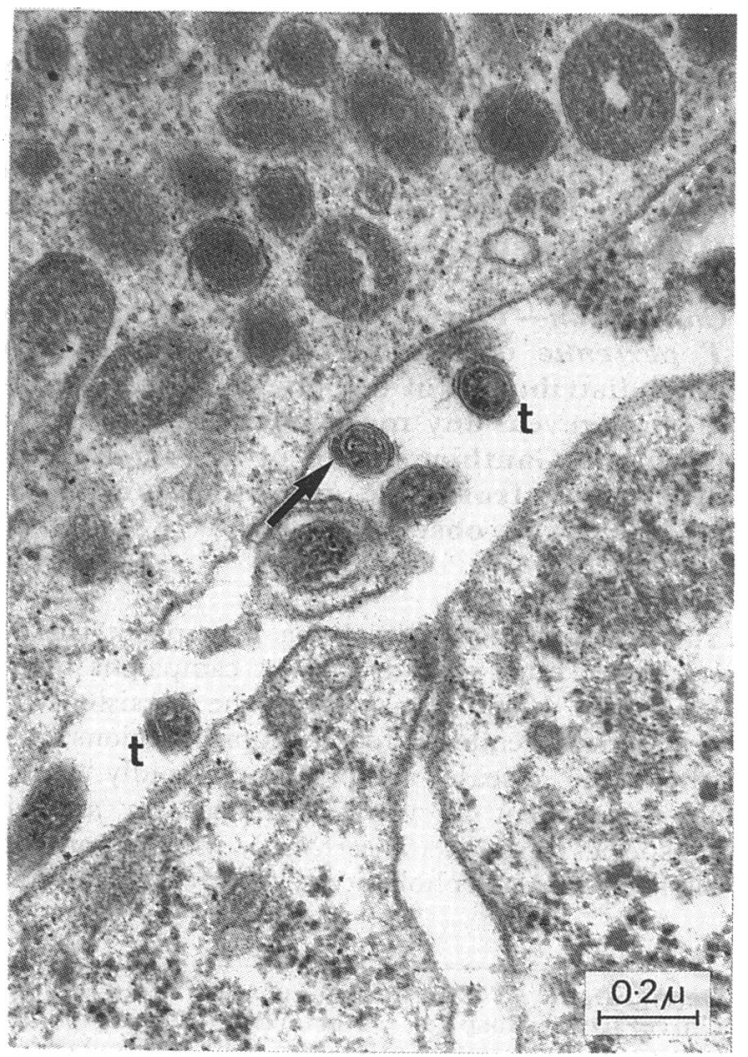

Figure 2 Transversally cut treponemes ( $t$ ) near inflammatory cells, showing their normal architecture. The membrane has a lamellar structure and axial filaments (arrow) are clearly visible (human skin, magnification $30000 \times$ ). 


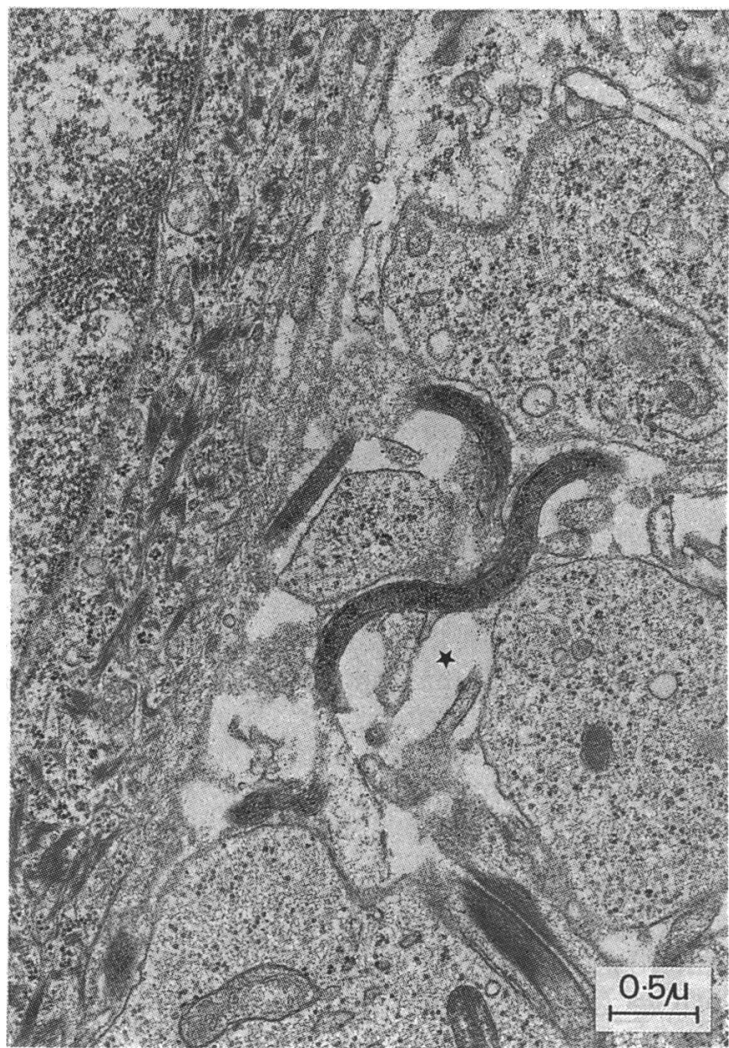

Figure 3 The epidermis shows spongiotic (asterisk) changes (dilatation of intercellular spaces). In these areas there are numerous treponemes. Epidermal cells show no disruption of cytoplasmic membranes. Human tissue, magnification $12000 \times)$

In the rabbit specimens, in one out of five specimens many treponemes were seen among inflammatory cells (figs 5, 6). In the other four rabbit samples no treponemes could be detected by electron microscopy. In the only positive specimen, many treponemes were found in the interstitial spaces of the testis. They were concentrated around fibroblasts, mesenchymal cells, the interstitial cells of Leydig and small blood vessels. Some treponemes were observed in close contact with mononuclear cells. Some treponemes were seen in cellular invaginations, without evidence of membrane disruption or fusion of the microorganisms with the cellular membrane. No differences could be detected between the morphology of treponemes in rabbit and human tissue.

\section{Discussion}

Ultrastructural studies have been of great significance for the classification of spirochetes. ${ }^{112}$ The presence of axial filaments is characteristic of this species of microorganisms. ${ }^{13}$
Most ultrastructural studies on pathogenic treponemes have been done on $T$ pallidum, compared with the very few on $T$ pertenue, ${ }^{5-8}$ in which only the Gauthier strain of $T$ pertenue was used. ${ }^{11}$ HovindHougan et al pointed out a subtle morphologic difference between the causative agents of yaws and syphilis, namely the presence of thin fibrils at the periphery of negatively stained $T$ pertenue (Gauthier strain) in skin lesions and lymph node biopsies of experimentally infected hamsters. These structures termed "fimbriae" were only detectable in optimally stained preparations. ${ }^{8112}$ This finding has not been confirmed by other workers.

In our study $T$ pertenue showed an ultramicroscopic morphology identical to T pallidum (Nichols strain), a strain previously studied in our laboratory. ${ }^{14}$ It became clear that $T$ pertenue was very scarce, and primarily located in clusters. No morphologic differences were observed between the treponemes in human and rabbit tissue. Our observations of the Indonesian strain of $T$ pertenue were similar to those reported for the Gauthier strain. ${ }^{78}$

Intracellularity of $T$ pallidum has been proposed as a means to evade the immune response. ${ }^{15}$ Although it was shown that $T$ pallidum was located almost exclusively in the extracellular ground substance, some investigators nevertheless demonstrated the intracellular presence of treponemes in a variety of cells. $^{15-18}$ Intracellularly located treponemes were

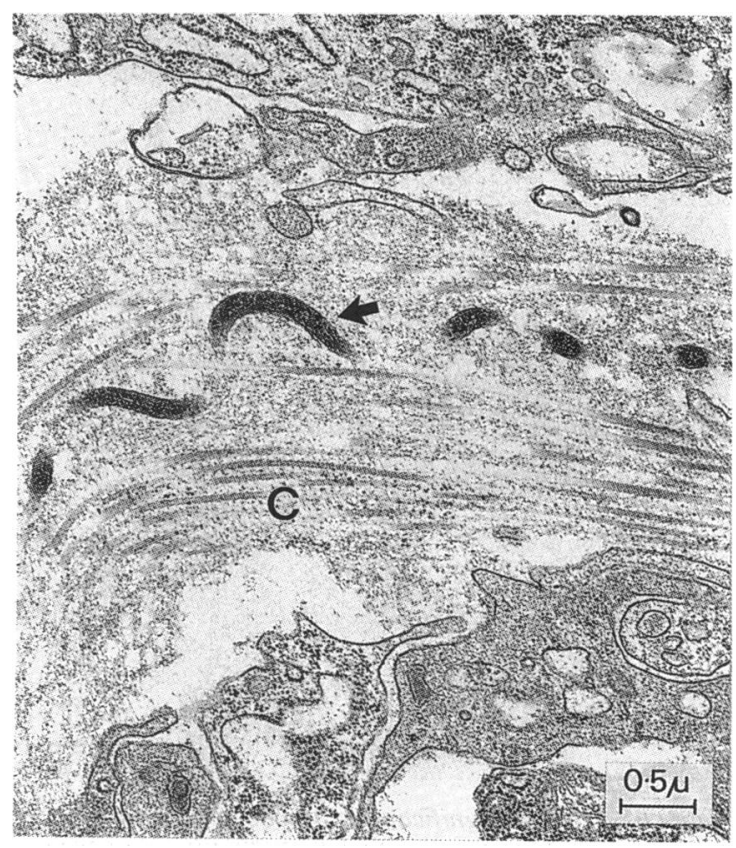

Figure 4 In the dermis between two fibroblasts among the collagen $(C)$ bundles treponemes (arrow) are visible (magnification $12000 \times$ ). 


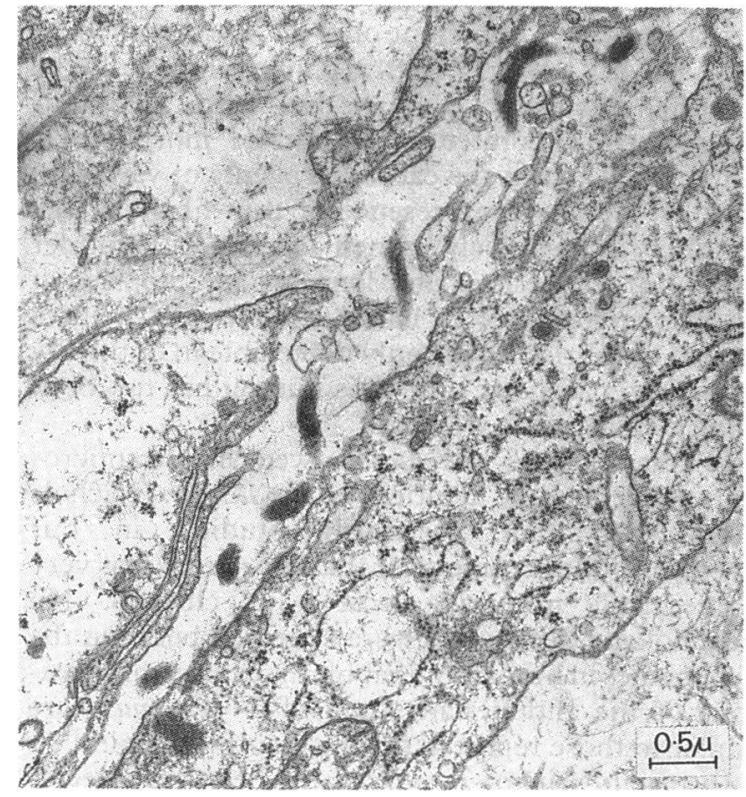

Figure 5 Interstitial tissue of the testes, with several fibroblasts lying in myxomatous stroma. Between the cells there are convoluted profiles of treponemes. Treponemes are lying in the myxomatous tissue, showing no adhesion to fibroblasts. Rabbit tissue, magnification $12000 \times$ ).

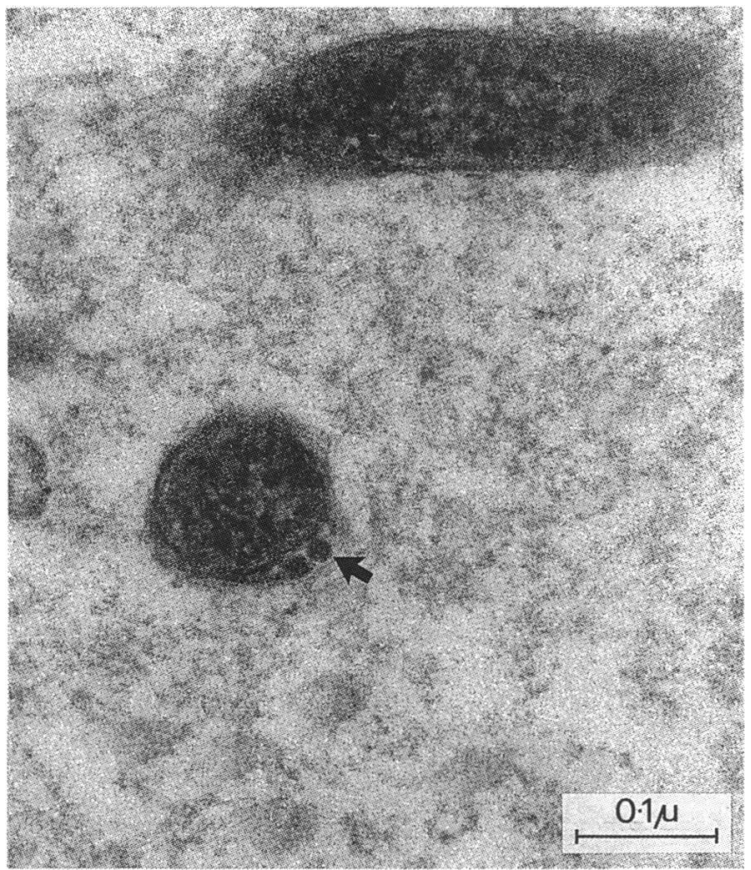

Figure 6 Higher magnification $(85000 \times)$ of two treponemes cut tangentially and longitudinally. Note their architecture: the outer membrane, axial filaments (arrow) and inner membrane are clearly visible. These $T$ pertenue microorganisms ultrastructurally show no differences from $T$ pallidum. assumed to be smaller, thicker and more electron dense. In our study the treponemes appeared to be located extracellularly, sometimes in close proximity to epidermal cells. It was observed that in some cases bacteria were engulfed by the cell membrane of phagocytic cells, and so came to lie in a membranous sac within the cytoplasm (a phagosome-like structure) with clearly preserved cellular membranes. These findings resemble those found with $T$ pallidum. ${ }^{715}$ This may represent intracellularity of $T$ pertenue. Much of the biology of yaws still remains unclear. Further study of this intriguing re-emerging disease is recommended.

The authors gratefully acknowledge the cooperation of Indonesian authorities and all patients, who gave permission for our investigations. We greatly appreciate the kind help of Dr Jubianto Judanarso and Dr R Iman Pandia from Jakarta, Dr M Soedarto from Padang, the Centers for Disease Control in Jakarta and Padang, and the nursing staff in the area of Pariaman. The authors thank all personnel of the Department of Pathology, personnel of the Laboratory Animal Center, M Kant and P C Onvlee, Erasmus University Rotterdam, the Netherlands, for helping us with this study. The Finsen Foundation, Rotterdam, sponsored this work. The Royal Dutch Airlines (KLM) transported all specimens free of charge.

Address for correspondence: $\mathrm{H} \mathrm{J} \mathrm{H}$ Engelkens, $\mathrm{MD}$, Department of Dermatology and Venereology, University Hospital Rotterdam-Dijkzigt, Dr Molewaterplein 40, 3015 GD Rotterdam, The Netherlands.

1 Engelkens $\mathrm{HJH}$, Jubianto Judanarso, Oranje AP, Vuzevski VD, Niemel PLA, van der Sluis JJ, Stolz E. Endemic Treponematoses. Part I. Yaws. Int J Dermatol 1991;30:77-83.

2 Engelkens HJH, Niemel PLA, van der Sluis JJ, Stolz E. The resurgence of yaws. World-wide consequences. Int J Dermatol 1991;30:99-101.

3 Programme for the Control of the Endemic Treponematoses. Geneva: World Health Organization. VDT/EXBUD/87.1; August 1987

4 Perine PL, Hopkins DR, Niemel PLA, St John RK, Causse G, Antal GM. Handbook of Endemic Treponematoses: Yaws, Endemic Syphilis, and Pinta. Geneva: World Health Organization, 1984.

5 Angulo JJ, Watson JHL, Courtney Wedderburn C, LeónBlanco F, Varela G. Electronmicrography of treponemas from cases of yaws, pinta, and the so-called Cuban form of pinta. $\mathrm{Am}$ $J$ Trop Med 1951;31:458-78.

6 Mölbert E. Vergleichende elektronenmikroskopische Untersuchungen zur Morphologie von Treponema pallidum, Treponema pertenue und Reiterspirochäten. Zeitschr Hyg 1956;142:510-5.

7 Ovčinnikov NM, Delektorskij VV. Treponema pertenue under the electron microscope. BrJ Venereal Dis 1970;46:349-79.

8 Hovind-Hougen $K$, Birch-Andersen A, Jensen HJS. Ultrastructure of cells of Treponema pertenue obtained from experimentally infected hamsters. Acta Pathol Microbiol Scand Sect $B$ 1976;84:101-8.

9 Jubianto Judanarso, Engelkens HJH, van der Stek J, Noordhoek GT, van der Sluis JJ, Stolz E. Current aspects of yaws in West Sumatra, Indonesia. Venereology 1991;4:9-11. 
10 Noordhoek GT, Engelkens $\mathrm{HJH}$, Jubianto Judanarso, et al. Yaws in West Sumatra: clinical symptoms, serology, and characterization of new Treponema isolates by DNA probes. Eur J Clin Microbiol Inf Dis 1991;10:12-19.

11 Hovind-Hougen K. Morphology. In: Schell RF, Musher DM eds. Pathogenesis and Immunology of Treponemal Infection, Immunology Series, vol 20, pp 3-28. New York: Marcel Dekker Inc, 1983.

12 Hovind-Hougen K. Determination by means of electron microscopy of morphological criteria of value for classification of some spirochetes, in particular treponemes. Acta Pathol Microbiol Scand Sect $B$ suppl no 255, 1976.

13 Holt SC. Anatomy and chemistry of spirochetes. Microbiol Rev 1978;42:114-60.

14 Van der Sluis JJ, ten Kate FJW, Vuzevski VD, Stolz E. Light and electron microscopy of rabbit testes infected with Treponema pallidum (Nichols strain): nature of deposited mucopolysaccharides and localisation of treponemes. Genitourin Med 1987;63:297-304.

15 Lauderdale V, Goldman JN. Serial ultrathin sectioning demonstrating the intracellularity of $T$ pallidum. An electron microscopic study. Br J Venereal Dis 1972;48:87-96.

16 Azar HA, Pham TD, Kurban AK. An electron microscopic study of a syphilitic chancre. Arch Pathol 1970;90:143-50.

17 Sykes JA, Miller JN. Intracellular location of Treponema pallidum (Nichols strain) in the rabbit testis. Infect Immun 1971;4:307-14.

18 Wecke J, Bartunek J, Stüttgen G. Treponema pallidum in early syphilitic lesions in humans during high-dosage penicillin therapy. An electron microscopical study. Arch Derm Res 1976;257:1-15.

Accepted for publication 15 July 1991 